\title{
DESENVOLVIMENTO ECONÔMICO SUSTENTÁVEL SOB A PERSPECTIVA DO DIREITO AGRÁRIO
}

\author{
SUSTAINABLE ECONOMIC DEVELOPMENT UNDER \\ THE PERSPECTIVE OF THE AGRARIAN RIGHT
}

\author{
Bruna Araújo Guimarães ${ }^{1}$ \\ Nivaldo dos Santos ${ }^{2}$
}

\section{RESUMO}

O presente trabalho versa sobre uma análise do princípio do desenvolvimento econômico sustentável sob a ótica da atividade econômica agrária, tendo em vista a crescente crise ambiental após a Revolução Verde e o surgimento dos complexos agroindustriais. Estuda-se o conflito jurídico entre os setores, objetivando o equilíbrio para a garantia plena ao meio ambiente, ao desenvolvimento econômico e à função da propriedade previstos na Constituição. Busca-se introduzir um estudo para se alcançar desenvolvimento sustentável agrário. A metodologia utilizada compreendeu a revisão bibliográfica da literatura correlacionada ao tema.

Palavras-Chaves: Direito Agrário; Direito Econômico; Meio Ambiente; Desenvolvimento Sustentável; Tecnologias Verdes; Agronegócio.

\begin{abstract}
The present work is about an analysis of the principle of the sustainable economic development under the optics of the agrarian economic activity, tends in view to growing environmental crisis after the Green Revolution and the emergence of agroindustrial complexes. It is studied the juridical conflict between the sectors, aiming the balance for the full guarantee to the environment, to the economic development and the function of the property foreseen in the Constitution. It is looked for to introduce a study to reach agrarian sustainable development. The methodology used understood the bibliographical revision of the literature related to the theme.
\end{abstract}

\footnotetext{
${ }^{1}$ Mestranda do Programa de Pós-Graduação em Direito Agrário da Universidade Federal de Goiás - UFG, (Brasil). Pós-graduada em Direito e Consultoria Empresarial e graduada em Direito pela PUC-GO. Bolsista da FAPEG. E-mail: adv.brunaguimaraes@ gmail.com

${ }^{2}$ Doutor em Direito pela Pontifícia Universidade Católica de São Paulo, PUC-SP, (Brasil). Professor Titular da UFG e PUC-GO. E-mail: nivaldodossantos@bol.com.br
} 
Keywords: Agrarian Right; Economic Right; Environment; Sustainable Development; Green Technologies; Agribusiness.

\section{INTRODUÇÃO}

O meio ambiente é bem essencial à vida e à saúde de todos, com reflexos na sobrevivência das presentes e futuras gerações, mas o homem, na tradicional concepção de domínio sobre tudo que existe na Terra passou a utilizar tais recursos de forma indiscriminada para fomentar o crescimento econômico sob uma lógica imaginária de que a qualidade de vida estaria pautada na riqueza e na tecnologia.

Os seres humanos, na intenção de acumular e circular capital divorciaram a relação da sua existência com o meio ambiente. Esse comportamento degradador do homem sobre a natureza gerou e gera impactos catastróficos no âmbito planetário, instalando-se a crise ambiental globalizada.

Com efeito, o mundo passou a almejar o desenvolvimento socioeconômico, o qual se expandiu na era industrial, quando iniciou o aumento acelerado dos processos produtivos com a utilização desmedida dos recursos naturais, principalmente após a estratégica Revolução Verde pós-guerra mundial, afetando diretamente a produção agrícola mundial.

Sendo assim, o tema deste artigo versa sobre alguns estudos iniciais sobre os mecanismos de compatibilidade da proteção do meio ambiente e do progresso econômico em busca do desenvolvimento sustentável agrário, equilíbrio essencial para a concretização do direito fundamental ao meio ambiente saudável e equilibrado, da função social da propriedade e do desenvolvimento econômico previstos na Constituição Federal de 1988.

A abordagem metodológica utilizada foi a leitura da bibliografia apresentada a fim de colacionar o posicionamento de vários autores sobre o tema, visando unificar o entendimento sobre a matéria, assim como a pesquisa de legislação nacional e estrangeira sobre o problema apresentado. 


\section{DESENVOLVIMENTO ECONÔMICO E O MEIO AMBIENTE}

A atividade econômica, no sentido constitucional, está ligada à apropriação privada dos meios de produção e à livre iniciativa, e tem por fim assegurar a todos a existência digna conforme os ditames da justiça social e alguns princípios, tais como a propriedade privada e a sua função social, livre concorrência, redução das desigualdades regionais e sociais, busca do pleno emprego, defesa do meio ambiente, entre outros.

O Desenvolvimento Econômico no Brasil está previsto no artigo 170 da Constituição Federal de 1988 e esquematiza a estrutura do ordenamento econômico do país, como meio de recomendar e regular as atividades econômicas. Segundo Derani (2008, p. 41) "o Direito Econômico pode ser compreendido como instrumento de política econômica e como um direito político", consequentemente, visa a manutenção do sistema produtivo e constitui o conjunto das relações econômicas e sociais.

Com relação aos objetivos da ordem econômica previstos no caput do artigo 170 da Magna Carta, Derani (2008, p. 236) destaca que a finalidade estaria em assegurar a todos existência digna, conforme os ditames da justiça social, sendo que "estes preceitos são a razão de todo texto sob o título da ordem econômica e financeira da Constituição Federal”.

Assim sendo, o sistema econômico pode ser definido como a reunião dos diversos elementos participantes da produção de bens e serviços que satisfazem as necessidades humanas da sociedade, organizados não somente no fator econômico, mas também nos fatores social, jurídico e político (NUSDEO, 2005).

Nesse contexto, por exemplo, ao tratar de justiça social e desenvolvimento, Grau (1991, p. 56) discorre que "a justiça social compreende bem-estar geral da comunidade, mesmo porque a disseminação do bem-estar pela comunidade é resultante daquela melhoria”.

Entretanto, embora o desenvolvimento econômico pretenda uma proteção do meio ambiente, a natureza acaba por ceder à economia, sob pena de não evolução das atividades econômicas e sociais, que segundo Barros (2010, p.21) “deve haver interação entre o meio ambiente e o desenvolvimento humano, exteriorizado pelas condicionantes do direito positivo. Para estes, o meio ambiente é aquilo que o direito expõe ser”.

A interligação do direito econômico com o direito ambiental conduz para que a economia atenda as finalidades sociais, com o fim de riqueza social e melhoria da vida na 
sociedade. Assim, a importância da interrelação entre os princípios constitucionais ambientais e os princípios constitucionais da ordem econômica, seu relacionamento e interdependência, salientam e priorizam a defesa ambiental.

Em tais condições, deu-se início a um processo de internalização do meio ambiente ao Direito Econômico, situação esta que (NUSDEO, 2005) apresenta ao indicar que os sistemas econômicos e ambientais correspondem a duas esferas concêntricas: a maior, o sistema ambiental, conteria a menor, o sistema econômico.

A Política Nacional do Meio Ambiente, no inciso I do artigo $3^{\circ}$, da Lei no 6.938 , de 1981, apresenta o conceito de meio ambiente, como sendo o "conjunto de condições, leis, influências e interações de ordem física, química e biológica, que permite, abriga e rege a vida em todas as suas formas".

Quando se debate sobre meio ambiente, entende-se este como o espaço físico, integrado pelos seres bióticos e pelos componentes abióticos, independentemente da amplitude geográfica, relacionada ou não com a atividade humana, pois as ações antrópicas também provocam impactos ambientais.

Assim é que o meio ambiente deve ser interpretado como um bem jurídico complexo, pois engloba os elementos naturais como a água, o ar atmosférico, o solo, a flora e a fauna, inclusive o próprio ser humano, e também os elementos culturais e artificiais, como os equipamentos urbanos e os edifícios construídos pelo ser humano (SCHONARDIE, 2005).

Nesse sentido, o artigo 225, da Constituição Federal de 1988 ressalta o caráter patrimonial do meio ambiente e fundamenta o conceito ao referir-se sobre o equilíbrio ecológico e a sadia qualidade de vida. Conservar o meio ambiente é, portanto, uma atribuição do Poder Público e de toda a sociedade.

Em relação à amplitude da conceituação do ambiente, pode dizer que se protegem os elementos bióticos e abióticos e sua respectiva interação, porque este bem é responsável pela conservação de todas as formas de vida (MILARÉ, 2011).

A imanente necessidade de expansão produtiva da atividade econômica acarreta na subordinação de toda relação ser humano e natureza a uma única e suficiente ação apropriativa, a natureza passa a ser exclusivamente recurso, elemento da produção e objeto da apropriação humana (DERANI, 2008).

Segundo Leite (2003), o conflito entre ser humano e natureza existe desde que aquele surgiu na Terra, em decorrência da necessidade de adequação do meio ambiente às suas 
necessidades, somada ao fato destas serem ilimitadas, em oposição à finitude dos recursos naturais. Este conflito foi se agravando com o advento de novas tecnologias, possibilitando ao ser humano ir além da mera subsistência de consumo, buscando maiores níveis de produção, o que caracterizou um modelo de apropriação dos recursos naturais, baseado no paradigma antropocêntrico utilitarista.

Aliás, a preservação do meio ambiente é uma obrigação de todos em benefício da coletividade, tanto das gerações presentes quanto das sucessivas. Com efeito, a natureza não pode ser explorada de forma desarmônica com a sustentabilidade ambiental, tendo o desrespeito à ordem protetiva do meio ambiente, implicações administrativas, civis e penais. (DERANI, 2008).

O desenvolvimento é um processo que supõe a ação do ser humano sobre os bens da natureza, que objetiva a satisfação do interesse individual e coletivo. Zambam (2012, p. 126127) considera o desenvolvimento como um processo que estabelece relações equilibradas do ser humano com os seus semelhantes, "com a estrutura social, os recursos tecnológicos e ambientais, e a preocupação das condições de vida das futuras gerações, caracterizadas como sujeitos de direito".

Sen (2010) acrescenta que existe um conflito entre liberdades políticas e a satisfação das necessidades econômicas. No entanto, há poucas evidências de que o Estado imperativo e a supressão de direitos políticos e civis sejam benéficos para incentivar o desenvolvimento econômico. Igualmente, em relação ao crescimento econômico, à democracia e a liberdade dos direitos civis e políticos da população.

A partir da segunda metade do século XX começa nos Estados Unidos, Canadá e na Europa - mais especificamente no Reino Unido - a surgir a concepção de ética dos negócios, baseada na credibilidade que a empresa deveria ter perante a sociedade (PEREIRA, 2006). A confiança converte-se novamente em valor empresarial e as empresas são levadas a pensar em resultados mediatos, entendo, outrossim, que suas ações deveriam ser pensadas tendo em vista o futuro e suas decisões passíveis de responsabilização.

Essa ética empresarial seria uma espécie dentro do gênero da ética das organizações, a qual tem como objetivos: determinar qual é o fim específico (bem interno) da organização, pois é em função deste fim que a organização tem sua legitimidade; verificar quais são os meios adequados para produzir os bens e quais valores são necessários para alcançar esses fins; quais são os hábitos que a organização deve adquirir que possibilite e demonstre a 
incorporação desses valores de modo a permitir que as tomadas de decisões sejam de acordo com essas metas (fins); saber como as organizações devem se portar frente às atividades, demais organizações e os bens externos e internos a elas (CORTINA, 2008).

É certo que a empresa deve estar em harmonia com determinado meio social, e para isso, "o desafio das empresas que querem ser reconhecidas como socialmente responsáveis é desenvolver mecanismos de interação democrática com seus parceiros estratégicos, tais como as comunidades locais" (FABIÃO, 2000, p. 73).

O novo modelo de desenvolvimento deve situar o ser humano como centro do processo de desenvolvimento e considerar o crescimento econômico como um meio e não como um fim; precisa proteger as oportunidades de vida das gerações atuais e futuras e respeitar a integridade dos sistemas naturais que possibilitam a existência de vida na Terra. Isso implica redefinir o desenvolvimento econômico, percebido como um fim em si mesmo, e criar as condições para superar o paradigma da modernidade, fundado no atual modelo econômico, expresso no domínio do poder sobre a natureza e os outros (CORRÊA; BACKES, 2006).

Portanto, diante da sociedade de risco e da complexidade social, torna-se impossível a concepção de vida e do ser humano sem interferência no meio ambiente natural, e atribui-se ao Direito e à Economia o dever de orientar o comportamento dos indivíduos na sociedade. Contudo, ante a impossibilidade do Direito Ambiental assegurar absoluta proteção ambiental, esse sistema deve ser completado pelo equilíbrio entre meio ambiente e economia, para a concretização do direito fundamental ao meio ambiente ecológico e equilibrado para as presentes e futuras gerações.

\section{REVOLUÇÃO VERDE NO BRASIL E O SURGIMENTO DO COMPLEXO AGROINDUSTRIAL}

Sob o argumento de colocar o país na seara de agricultura industrial e elevar a economia lucrativa do setor, deu-se início à chamada Revolução Verde, um aglomerado tecnocientífico que dizia priorizar o desenvolvimento sustentável dos modos rurais de produção agrícolas, na década de 1970 (BECK, 1989).

No entanto, diversos autores afirmam que o ocorrido foi totalmente o oposto, além da Revolução Verde não ter resolvido o problema alimentar, também propiciou o aumento da concentração fundiária e a dependência de sementes, alterando a cultura dos proprietários 
pequenos que encontraram inúmeras dificuldades para se inserir no novo padrão, além de levá-los ao endividamento, vez que o lucro decorrente da atividade agrícola foi transferido para a agroindústria.

Segundo Andrades e Ganimi (2007), a Revolução Verde não foi apenas um avanço técnico para aumentar a produtividade, mas também houve uma intencionalidade inserida dentro de uma estrutura e de um processo histórico.

Andrades e Ganimi (2007) argumentam ainda, que já findada a Segunda Guerra Mundial, muitas indústrias químicas que abasteciam a indústria bélica norte-americana, começaram a produzir e a incentivar o uso de agrotóxico: herbicida, fungicida, inseticidas e fertilizantes químicos na produção agrícola para eliminar fungos, insetos, ervas daninhas (ROSA, 1998 apud ANDRADES E GANIMI, 2007) e o maquinário pesado como tratores e colheitadeiras, formando pacotes tecnológicos.

Os mesmos autores acima relatam que o problema da fome tornava-se cada vez mais sério em várias partes do mundo e o governo americano e os grandes capitalistas temiam que se tornasse elemento decisivo nas tensões sociais existentes em muitos países, o que poderia ampliar o número de nações sob o regime comunista, particularmente na Ásia e na América Central, tradicionais zonas de influência norte-americana (ROSA, 1998, p. 19 apud ANDRADES E GANIMI, 2007). Desse modo, as bases técnicas da Revolução Verde estavam lançadas, mas faltavam ainda os aspectos sociais, políticos e econômicos para implantação, de fato, do processo de modernização da agricultura.

$\mathrm{O}$ processo de industrialização da agricultura brasileira ocorreu então em um mercado com fortes características oligopólicas e para Müller foi neste contexto que se constituiu no Brasil o Complexo Agroindustrial, definido como (1989, p. 48):

O conjunto de processos técnico-econômicos, sóciopolíticos, que envolvem a produção agrícola, o beneficiamento e sua transformação, a produção de bens industriais para a agricultura e os serviços financeiros correspondentes.

Neste contexto, ainda aduzem Locatel e Azevedo (2008):

O processo de modernização da agricultura brasileira, incentivado por políticas públicas bem definidas, a partir da década de 1960, passa a ser considerado sinônimo de desenvolvimento rural, havendo uma simplificação típica da chamada teoria da modernização e do crescimento, onde os efeitos sociais positivos do desenvolvimento econômico eram vistos como 'conseqüências naturais' dos processos de crescimento e de modernização, sem se admitir a necessidade de implantação de políticas de redistribuição da riqueza e de combate à pobreza. 
Outros fatores que contribuíram para as transformações ocorridas na década de 1960 foram as condições favoráveis do mercado internacional que, somadas ao crescimento da demanda do mercado interno, passaram a exigir um crescimento superior ao que vinha ocorrendo até então, através da incorporação de novas terras nas áreas de fronteira (LOCATEL E AZEVEDO, 2008).

Resumidamente, pode-se dizer que o crescimento da produção agrícola brasileira, até meados da década de 1960, apoiou-se em um modelo de agricultura extensiva que se caracterizou pelo crescimento da área plantada dentro dos latifúndios mercantis, pela expansão da fronteira agrícola e pelo baixo nível tecnológico (LOCATEL E AZEVEDO, 2008).

Locatel e Azevedo (2008) exemplificam como em nada foi verde a dita Revolução:

\begin{abstract}
A pequena elevação dos índices de uso de tratores e de adubos químicos, à base de nitrogênio, fósforo e potássio (NPK), que foram estimulados e facilitados pelo governo através da isenção de tarifas alfandegárias sobre a importação desses produtos e de financiamento favoreceu a incorporação destes à agricultura.
\end{abstract}

No Brasil, o conceito de complexo industrial foi formulado por HAGUENAUER et al (1984) e teve como ponto de partida a premissa de que em um espaço econômico determinado pode-se isolar um conjunto de atividades fortemente interdependentes. Desta forma, a constituição de um complexo industrial parte do processo de produção industrial, reunidos em cadeias produtivas que se "constituem em um espaço unificado de geração e apropriação de lucro e de acumulação de capital" (1984, p.2).

Entenda-se por Complexo Agroindustrial o conjunto de relações entre indústria e agricultura na fase em que esta mantém intensas conexões para trás, com a indústria para a agricultura e para frente, com as agroindústrias e outras unidades de intermediação que exercem impactos na dinâmica agrária. O Complexo Agroindustrial é uma forma de unificação das relações entre os grandes departamentos econômicos com os ciclos e as esferas de produção, distribuição e consumo, relações estas associadas às atividades agrárias. (MÜLLER, 1989).

De acordo com Müller (1982), o conceito de Complexo Agroindustrial (CAI) é semelhante ao do agronegócio (ou agribusiness) e, portanto, "pode ser definido como um conjunto formado pela sucessão de atividades vinculadas à produção e transformação de produtos agropecuários e florestais". Segue o Autor, explicando que todas as atividades estão englobadas, como a geração de produtos, transformação e a produção de bens e insumos para as atividades agrícolas, bem como a coleta, o transporte, a armazenagem e a distribuição dos 
produtos e até mesmo o financiamento, pesquisa e a tecnologia.

Müller (1989), ao analisar a gênese e a expansão do complexo agroindustrial no Brasil, teve como noções iniciais os conceitos de agribusiness e de complexo industrial. Em sua análise das transformações da agricultura brasileira, entende o Autor que parte da concepção de que esta se industrializou, e, para o mesmo, trata-se de sustentar que a atual industrialização do campo brasileiro é um fenômeno novo e que a agricultura industrializada imprime a direção do devir de toda a agricultura nacional.

De um lado houve um ganho de produção e produtividade com um consequente aumento da renda agrícola; de outro estão os resultados indesejáveis , com a expulsão da mão-deobra rural para os centros urbanos ou outras áreas de fronteira agrícola, e ainda, com a exclusão de produtores que não conseguiram incorporar-se à modernização.Müller (1989, p.53) classifica três grupos sociais resultantes da modernização agrária, fora àquele que emigrou dos campos:

\footnotetext{
O maior deles habita em estabelecimentos rurais que servem como moradia da família. Pode contar com alguma produção mercantil tradicional, mas com o predomínio da produção para subsistência. Pequenos proprietários, meeiros, ocupantes, cuja característica básica é a pobreza moderna, juntamente com o fato de serem mão-de-obra para a economia geral.
}

O Complexo Agroindustrial constituiu-se portanto em um dos motivos de transformação do setor agropecuário brasileiro. Ressaltando que neste processo houve a participação do capital industrial e do Estado (através do aparato financeiro - crédito rural) e dos grandes e médios proprietários. Ocorreu que fusão de capitais e a agricultura passou a ser tida como um campo de aplicações de capitais em geral (MAFARON, 2016).

GRAZIANO DA SILVA (1996, p.83) critica MÜLLER (1990, p.15), ao não concordar com a noção de Padrão Agrário Moderno, por considerar que tal conceito pode acentuar, ainda mais, uma falsa noção de homogeneidade da produção capitalista no campo entre ramos distintos como, por exemplo, entre a pecuária e a horticultura. Aliás, Harvey (1962) já ensinava que renda é simplesmente um pagamento ao proprietário rural pelo direito de usar a terra e seus acessórios, vez que a forma de exploração desenvolvida pelos latifundiários rurais é a renda fundiária.

Evoluindo para a última década, Flávia Trentini (2012) alega que a agricultura moderna impõe uma mudança à atividade agrícola tradicional, "os agricultores estão incumbidos, segundo a opinião pública dominante, de conjugar as atividades agrícolas de 
proteção ambiental e valorização da paisagem rural”.

Passando pela Revolução Verde e do surgimento dos Complexos Agroindustriais, agora o Direito Agrário transforma-se novamente, inovando seu instituto ao basear-se na atividade agrícola como empresa agrária que visa agora contratos agrários e mercados diretos (agronegócio), aumentando ainda mais a importância socioambiental da agricultura - o chamado Desenvolvimento Agrário Sustentável.

\section{PRINCÍPIO DO DESENVOLVIMENTO ECONÔMICO SUSTENTÁVEL}

Antes de estudar o Desenvolvimento Agrário Sustentável, mister se faz compreender o que é Desenvolvimento Sustentável, sendo este conceituado como um conjunto de medidas instituídas para satisfazer as necessidades da população, respeitando normas ecológicas de forma a não prejudicar o desenvolvimento das gerações futuras (NUSDEO, 2005).

A destrutiva dominação a que o ser humano submeteu o meio ambiente alcançou um estágio sem precedentes. Isso induz a rever os fundamentos das concepções hoje dominantes a respeito do ser humano e de seu sentido, enquanto partícipe da vida no planeta Terra. Nesse sentido, "nossa civilização luta incessantemente para gerar e comercializar riquezas. Na luta por estes objetivos, imergimos em um ambiente em constante desintegração dos recursos naturais e do ser humano, correndo o risco de gerar um mundo artificial" (MEDEIROS, 2007, p.15).

Nesta seara é polêmico o conceito de desenvolvimento sustentável, tendo em vista ser o próprio desenvolvimento o causador dos danos ambientais. Na busca desenfreada pela mudança, pela evolução, o ser humano acabou sendo sua própria vítima, com sua ação predatória. Verifica-se é que o ser humano não se percebe como parte integrante do meio ambiente. Essa concepção é consequência da cultura racionalista moderna, baseada na dualidade ser humano e natureza, ou seja, o ser humano está fora e acima da natureza, vista como objeto externo ao sujeito humano que, pela ciência e a tecnologia, explora sem limites os recursos naturais (CORRÊA; BACKES, 2006).

A definição de "Desenvolvimento Sustentável" surgiu na Comissão Mundial sobre Meio Ambiente e Desenvolvimento (1987), criada pela Organização das Nações Unidas (ONU), em 1983, para reexaminar as questões problemáticas relativas ao meio ambiente e criar plataformas reais para abordá-las, bem como propor novos formatos de cooperação internacional para orientar as ações e políticas no sentido das mudanças necessárias, com o 
dever de possibilitar aos indivíduos, organizações não governamentais, empresas, institutos e governos uma amplitude maior de compreensão de seus problemas relativos, buscando um aprimoramento para uma atuação mais firme nesse sentido (NUSDEO, 2005).

No mesmo ano de 1987, a comissão recomendou a elaboração de uma declaração universal sobre a proteção ambiental e o desenvolvimento sustentável, o Relatório Brundtland, cujo título foi "Nosso Futuro Comum". O discurso principal foi o de relacionar o desenvolvimento econômico à questão ambiental, criando não apenas um novo termo, mas uma nova forma de olhar o futuro (NUSDEO, 2005).

Significa que é necessário caracterizar o desenvolvimento sustentável como um processo lento, eficaz e seguro, pois a natureza é portadora dos meios necessários para a sobrevivência humana e das demais espécies (CAPRA, 2006).

O desenvolvimento sustentável baseia-se na premissa de que o crescimento econômico e a qualidade ambiental precisam caminhar juntos, no entanto, segundo Bernardes e Ferreira (2009) um dos propósitos do capitalismo consiste em exercer o domínio e o controle sobre a natureza, com a pretensão de auferir lucro sobre os bens ambientais e os serviços produzidos pelo trabalho humano.

O processo da natureza evidencia as características e peculiaridades específicas e as ameaças do modelo atual de desenvolvimento, com interesses individualistas. A desunião do direito econômico dos valores sociais e do meio ambiente instaura um verdadeiro conflito socioeconômico ambiental.

Ao estabelecer, por exemplo, o princípio da responsabilidade, Jonas (2006, p. 18) afirma que "está pensando menos no perigo da destruição física da humanidade, mas sim na sua morte essencial, aquela que advém da desconstrução e reconstrução tecnológica do homem e do ambiente". O princípio da responsabilidade tem que ter um significado ético, não pode referir-se unicamente à natureza como abstração, mas antes ao meio ambiente natural da vida humana.

A partir da análise desses problemas constrói-se o conceito de desenvolvimento econômico - neste já incluso o sentido de sustentabilidade - levando-se em conta não somente o crescimento econômico, mas também a melhoria e garantia de melhores e mais saudáveis padrões de vida à população (bem estar social), coordenada com um equilíbrio na distribuição de renda, posse de bens materiais e aumento da capacidade de consumo. Isso se reverteria em condições materiais ao bem-estar da sociedade (manutenção da sanidade física e psíquica dos 
indivíduos): acesso à alimentação sadia, qualidade da água que se consome, disponibilidade para o lazer, índice de salubridade do ambiente de trabalho etc (DERANI, 2005).

É por meio do balanço social que a sociedade saberá como a empresa está - e se está - cumprindo seu papel social. "Os resultados dessas ações, desempenhadas pelas empresas, encontram no Balanço Social o local para sua divulgação e visibilidade à opinião pública em geral" (MEDEIROS, 2007, p. 35), quais sejam:

a) A empresa mostra à sociedade que utiliza parte de seus recursos em projetos, em ajuda financeira a organizações não-governamentais, na criação de institutos ou fundações para fornecer serviços e bens públicos ou para defender causas sociais, ecológicas, educacionais e quaisquer outras atividades envolvendo os cidadãos.

b) A empresa se relaciona de maneira correta com seus fornecedores, com as demais empresas que atuam na mesma atividade (concorrentes) e com os consumidores. Mas esse agir não é simplesmente guiado pelos princípios da livre concorrência, livre iniciativa e respeito aos consumidores conforme a função social determina. É uma atuação que vai além, com a criação de conselhos, projetos e ajuda a organizações que miram a conscientização do consumidor.

c) A empresa socialmente responsável prima pelo investimento em educação, cursos profissionalizantes e quaisquer outros tipos de atividades que primem por explorar e incentivar ao máximo a capacidade, criatividade e habilidade de seus funcionários.

No Brasil, a Associação Brasileira de Normas Técnicas (ABNT), como representante oficial da ISO no país, editou o Sistema de Gestão da Responsabilidade Social mediante a NBR 16001, validada em 30 de dezembro de 2004, que não é um dispositivo obrigatório e nem confere à empresa uma "certificação" ou qualquer tipo de atestado demonstrando que a empresa é socialmente responsável, mas apenas indica que aqueles que seguirem as diretrizes nela estabelecidas possuem um sistema de gestão de responsabilidade social.

Além das certificações, códigos de conduta, pactos e diretrizes criados em âmbito internacional, que ajudam a sociedade a discutir sobre o papel da empresa e auxilia o Estado no momento de positivar normas a respeito da responsabilidade social, tem-se na esfera interna a Ordem Econômica e Financeira delineada no art. 170 da Constituição Federal de 1988, cujos princípios nele constantes trazem exatamente o substrato para se desenvolver a concepção de responsabilidade social.

O fato é que um aumento na eficiência da produção não constitui pré-condição adequada para a satisfação plena das necessidades básicas da população. Além disso, um aumento na disponibilidade de recursos e uma elevação nos padrões de vida podem ocorrer na 
ausência de qualquer mudança no processo de produção, como o aumento da pressão sobre as reservas naturais dos recursos não renováveis (SILVA, 2009).

Segundo Marques (2011), o desenvolvimento sustentável deve ser considerado como meta, como objetivo do Poder Público e da comunidade. Contudo, o que não se pode aceitar é a insustentabilidade ambiental e social em benefício do crescimento econômico. A Constituição Federal de 1988, no artigo 170, inciso VI, refere-se à defesa do meio ambiente como um dos princípios da atividade econômica, que deve ser compatibilizado com a preservação do meio ambiente e a qualidade de vida da população.

\section{DESENVOLVIMENTO SUSTENTÁ VEL AGRÁRIO}

A Constituição Federal do Brasil, em seu artigo $3^{\circ}$, incisos I a IV, presa por uma sociedade livre, justa e solidária, com erradicação da pobreza, da marginalização e a promoção do bem-estar de todos, sem preconceitos e discriminação, para garantir o desenvolvimento nacional, que só acontecerá se acompanhado da promoção da dignidade humana e diminuição das desigualdades sociais.

Assim, paralelamente ao princípio do Desenvolvimento Econômico Sustentável, e diretamente a este relacionado, ganha enfoque o Desenvolvimento Sustentável Agrário, vez que neste, dentre outros objetos, está o consagrado direito à alimentação.

Ademais, a Carta Magna, estabelece o direito à alimentação como objetivo constitucional da dignidade da pessoa humana, que, aliás, enquanto um direito social é essencial para a realização do direito à vida.

Nas nações em desenvolvimento a poluição ambiental e a fome são extremas e o progresso nada tem feito para pausá-las, o que é alarmante, vez que as duzentas maiores sociedades agroalimentares do mundo controlam 1/4 da produção alimentar (ZIEGLER, 2013).

A China, por exemplo, enfrenta problemas ambientais à medida que se esforça para avançar economicamente a todo custo, na África, crianças, jovens e adultos, a população como um todo, ainda continua morrendo por não ter condições mínimas de sobrevivência.

Conforme aduz Ziegler (2013) se queremos que o comércio seja favorável ao desenvolvimento e que contribua para a realização do direito a uma alimentação suficiente, é preciso reconhecer a especificidade dos produtos agrícolas, em vez de assimilá-los a uma 
mercadoria como qualquer outra.

Nesse contexto, ganha destaque o modus operandi de se alcançar a plenitude do direito à alimentação, qual seja, o desenvolvimento econômico agrário, que só será plenamente alcançado através da utilização de mecanismos sustentáveis.

A política do desenvolvimento econômico busca a regulação e organização de mercado, que segundo Derani (2008, p. 48) "são indissociáveis os fundamentos econômicos de uma política ambiental consequente e exequível. E uma política econômica consequente não ignora a necessidade de uma política de proteção dos recursos naturais”.

Ocorre que no Brasil, e até no mundo, ainda predomina o modelo de produção agrícola com a elevada concentração da propriedade e grandes explorações monocultoras, extrativistas e agropecuárias, com intenso uso de tecnologia que nem sempre é a mais viável ambientalmente.

Entretanto, existem alguns economistas que defendem que o crescimento econômico não causa danos ao meio ambiente natural, pois isso só ocorreria em países pobres ou subdesenvolvidos. Por conseguinte, o meio ambiente desses países será beneficiado pelo crescimento econômico, quando atingirem os níveis máximos de renda per capita, já que a poluição ambiental consiste num problema de níveis mínimos de renda, numa crise de pobreza (VEIGA, 2006).

Ainda há outro fator, inobstante o constante crescimento da agricultura, nem sempre os alimentos chegam à população que os criou. A falta da alimentação, infelizmente, cresce nas mesmas proporções que o agronegócio, e assim, a fome continua se alastrando por todo planeta.

Especialmente no caso do Brasil, salvo raras exceções, o modelo do agronegócio ainda não vem buscando mecanismos elevados de inovações sustentáveis, ainda que seus países clientes estejam cada vez mais rigorosos e exigentes na forma da produção agrícola.

Ensina Bosselmann (2015) que hoje estamos em uma situação profundamente diferente, o mundo globalizado atingiu tal nível de complexidade que tornam impossíveis soluções rápidas, já que métodos tradicionais de sustentabilidade não farão muita diferença.

Segundo a Cortina (2008), a "empresa" precisa legitimar sua existência e atuação mediante a confiança do consumidor, fazendo-o preferir sua empresa e produtos não somente pela eficiência de seus serviços, mas pela crença de compartilhamento dos mesmos valores éticos adotados pela sociedade. Nesta esteira, pode-se entender que as "empresas" são tão 
responsáveis quanto o são os indivíduos.

Uma forma de proporcionar a coexistência é listada por Lustosa (2011) que defende que um caminho para diminuir o nível dos impactos ambientais, seria através das inovações tecnológicas. A inovação ambiental (IA) poderia servir como via de mudança no padrão tecnológico rural atual, substituindo o uso extensivo das matérias primas, mudando estruturalmente a forma de produção em direção a uma economia mais sustentável.

As tecnologias verdes trazem novas técnicas que se preocupam com os impactos gerados através das atividades humanas, devendo por tais razões serem incorporadas à cadeia de produção agrícola. Tais tecnologias não se preocupam apenas com os processos produtivos, mas com a destinação dada aos produtos ao longo do tempo, a possibilidade de reciclagem e a transformação após a utilização. Com essa mudança, seria possível reduzir consideravelmente o impacto atual que as atividades econômicas têm no meio ambiente. Vejamos alguns exemplos que já foram apresentadas ao Instituto Nacional da Propriedade Industrial - INPI:

a) PI1104219-2, Processo de tratamento de resíduos sólidos baseado em gradiente composto por duas fontes térmicas distintas, que é uma técnica no processamento de resíduos sólidos por meio de fontes térmicas, em que os dejetos são filtrados em carvão ativado e queimados. A tecnologia trabalha sob descargas elétricas e os resíduos passam por um catalisador e depois por uma chaminé e são extravasados para a atmosfera. Não produzem cinzas e a emissão dos gases é reduzida e atóxica, permitindo uma real sustentabilidade (INPI, 2015);

b) PI0903048-4, Processo para produção de etanol a partir de soro de leite do queijo. A tecnologia apresenta as mesmas características do etanol produzido pela cana-de-açúcar, motivo pelo qual dispõe de um extensivo mercado para disposição final, o soro produz açucares fermentescíveis (glicose e galactose), que são fermentados e convertidos a etanol, produzindo assim o biocombustível limpo (INPI, 2015).

c) PI 1100645-5, Processo para transformação de vinhaça, que após concentrada, é seca em equipamento do tipo moinho-micronizador-secador transformando-se em pó seco, pode ser utilizado como fertilizante agrícola em geral ou como adubo (INPI, 2015).

O cenário brasileiro e mundial atual mostra a crescente crise ambiental e alimentar, sendo imperioso o estudo de mecanismos para seu combate, sendo as tecnologias verdes uma forma de efetivação do desenvolvimento econômico rural sustentável.

Aliás, esse tipo de atuação tem sido observada em função da lucratividade que o 
"mercado verde" tem se mostrado. Da mesma forma, vários países passaram a atuar de uma maneira mais rigorosa com a entrada de produtos que não obedecessem alguns padrões de conduta para a sua produção, sem contar a crescente pressão dos indivíduos, que deixaram de adquirir produtos e serviços que não estivessem em conformidade com os padrões básicos de responsabilidade socioambiental.

Além da questão das inovações tecnológicas, o "esverdeamento" da economia agrícola também poderia se alcançar por meio de investimentos em atividades de baixo impacto ambiental. Se o crescimento das atividades econômicas se der em áreas menos agressivas ao meio ambiente, por exemplo, já será possível haver uma considerada desaceleração no processo de degradação dos recursos naturais (DERANI, 2008).

A busca por uma boa qualidade de vida e a garantia de alimentação digna e erradicação da fome, são objetivos últimos tanto do direito econômico quanto do direito ambiental. (TAVARES, 2003).

Neste contexto algumas leis federais brasileiras também foram criadas com o propósito de regulamentar um sistema agrário sustentável, como é o caso da Lei n. 9.456/1997 que institui a Lei de Proteção de Cultivares, a Lei n. 9.985/2000 que cria o Sistema Nacional de Unidade de Conservação (SNUC), a Lei de Biossegurança n. 11.105/2005, a Lei n. 11.284/2006 de Gestão das Florestas Públicas, a Lei n. 12.305/2010 da nova Política Nacional de Resíduos Sólidos a e a Lei 12.561/2012 que abrange temas como áreas de preservação permanente, reserva legal rural, o próprio Código Florestal, dentre outras.

Em 2003, por exemplo, foi determinado pelo Decreto Presidencial n. 4.680/2003 a rotulagem de produtos transgênicos com um triângulo amarelo e um " $\mathrm{T}$ " preto ao centro, além de trazer informações sobre o OGM (organismo geneticamente modificado) no rótulo, para aqueles alimentos que contém mais de $1 \%$ de transgênicos em sua composição, sob pena de sanções administrativas, civis e até penais.

No âmbito internacional, podemos citar também o Tratado Internacional de Recurso Fitogenéticos para a Alimentação e Agricultura (TIRFAA), aprovado em Roma no ano de 2001 e assinado pelo Brasil em 2002, que visa promover a conservação e o uso sustentável de recursos fitogenéticos para alimentação e agricultura, bem como a repartição de benefícios decorrentes de seu uso, com vistas à segurança alimentar e agricultura sustentável.

Ainda na seara Internacional, grande polêmica gira em torno do Protocolo de Nagoya (2010) que versa sobre o Acesso e Repartição Justa e Equitativa de Benefícios, ainda não 
ratificado pelo Brasil inobstante a aderência de 51 países, sob a alegação de que aumentaria os custos da produção agrícola, mais especificamente no pagamento de royalties aos provedores de espécies exóticas cultivadas.

Face a constatação de que o Brasil não conseguiria cumprir as metas estipuladas, fora aprovado um Plano Estratégico para 2020, contendo 20 metas para conservação e uso sustentável da biodiversidade, conhecidas como Metas de Aichi.

Paralelamente, um dos meios para alcançar a coexistência entre proteção do meio ambiente e progresso empresarial agrário (dito agronegócio) também seria a extrafiscalidade instrumento jurídico utilizado pela Administração Pública com o escopo de, impositivamente, estimular ou desestimular condutas, prestigiando determinados valores ou interesses (BARBOSA, 2008).

Ademais, quanto à regulação do meio ambiente pelo mercado, há que se lembrar que o Agronegócio Sustentável passou a ser considerado como uma das áreas mais promissoras da economia mundial, tornando-se fator de interdependência econômica.

É preciso entender que o modelo ideal de trabalho e gestão em uma atividade empresarial (agrícola ou não) deve ser pautado por princípios que abarquem suas externalidades negativas para a sociedade e saiba demonstrar que o melhor caminho é o de um desenvolvimento sustentado por modelos que não causem danos ao meio ambiente, além de contribuir para a erradicação da fome, sendo o lucro apenas a consequência de tais atuações.

Frisa-se, tanto no Estatuto da Terra quanto na própria Constituição Federal a Função Social está no bem e não no direito ou no proprietário, prevendo em ambos os dispositivos da conservação dos recursos naturais e da manutenção de níveis satisfatórios de produtividade, devendo, por excelência, buscar meios de adequação de tais preposições (MARÉS, 2003).

Aliás, conforme enfatiza Marés (2003, p. 133):

\begin{abstract}
A produtividade da terra nos sistemas jurídicos que protegem o meio ambiente e buscam o desenvolvimento sustentável, somente pode ser entendida como um processo permanente, isto é, não pode ser considerada produtiva a terra que esgota os recursos naturais a ela associados e inviabiliza ou dificulta seu uso pelas gerações futuras.
\end{abstract}

Não há dúvidas de que o Agronegócio é um dos combustíveis do crescimento econômico do País, sendo um fator importante para o desenvolvimento. Mas, não se deve esquecer que no crescimento a mudança é quantitativa, enquanto no desenvolvimento é qualitativa. Os dois fatores estão ligados, mas com conceitos diferentes (VEIGA, 2006), 
sendo extremamente importante que mais estudos sejam feitos na área para se efetivar um Desenvolvimento Agrário Sustentável.

\section{CONCLUSÃO}

O presente estudo partiu de uma análise do tema "Desenvolvimento Econômico Sustentável", no que tange a aplicação de práticas socioambientais das sociedades empresariais rurais.

Pretendeu-se com este trabalho conhecer as questões relacionadas com o Direito Ambiental, Econômico, Empresarial e do Direito Agrário, sendo que para tanto, a abordagem metodológica utilizada foi o método dialético e analítico, utilizando o método históricosistemático para o desenvolvimento da pesquisa, além da leitura e estudo de diversos referenciais bibliográficos em envolvem o tema objeto deste estudo.

O Direito Ambiental e o Direito Econômico têm suas normas constitucionais interligadas, porquanto as finalidades dos preceitos ambientais, dispostos no artigo 225, devem servir de diretrizes para a atividade econômica, elencada no artigo 170 da Constituição Federal de 1988, pois os escopos de ambos os direitos são indissociáveis.

O próprio paradigma do Estado Democrático de Direito faz com que as atividades empresariais (agrícolas ou não) coloquem em discussão e procurem formas de efetivar valores e objetivos importantes à sociedade, pois correspondem aos seus anseios de produtividade, lucro e harmônica com a busca do desenvolvimento socioeconômico.

Percebe-se que a dificuldade do Estado, das empresas e da sociedade não consiste na opção entre crescimento e qualidade do meio ambiente, mas sim em buscar o justo equilíbrio entre a economia e a natureza com os objetivos socioeconômicos e ambientais. O objetivo do desenvolvimento sustentável representa a experiência de buscar o equilíbrio e a harmonia entre os fatores sociais econômicos e ambientais, bem como a redefinição dos padrões de uso dos recursos naturais e do atendimento das necessidades básicas da população e da empresa.

Um aspecto a ser implementado como forma de subsidiar o progresso empresarial rural sustentável, seria a efetividade das normas, ou até mesmo a criação de novas, de caráter socioambientais, que regulamentassem de forma mais severa as atuações do agronegócio em desconformidade com o desenvolvimento sustentável, tornando mais rígidas as fiscalizações e ao mesmo tempo proporcionando mais efetividade as práticas pró-ambientais. 
Aliás, a finalidade do progresso de um modelo de desenvolvimento econômico preocupado com a distribuição de riquezas e geração de lucro com a preservação dos recursos naturais, deve visar o bem-estar social e ambiental da população, aliados aos fatores econômicos e financeiros de um país.

O presente artigo teve como objetivo ressaltar a possibilidade e esperança de introdução de mecanismos sustentáveis ao agronegócio e, principalmente, de alertar que é ingenuidade imaginar que o setor deve recepcionar as melhores práticas de proteção ambiental sem qualquer contrapartida, sendo primordial ampliar e investir no conhecimento e a análise dos institutos verdes disponíveis, de tecnologias já aplicadas e bem sucedidas, de melhorias no fomento e divulgação e de outras situações que estão sendo debatidas por vários setores econômicos, classes sociais e pelos Estados, estes, em tese, os maiores interessados na proteção do meio ambiente e na erradicação da fome de sua população.

Não se nega a importância do Agronegócio e dos Complexos Agroindustriais, vez a economia está diretamente relacionada crescimento de uma nação e esta, com a garantia da alimentação aos cidadãos, sendo primordial, entretanto, que todos os desenvolvimentos se realizem de maneira sustentável e consciente, aliando o socioeconômico com a preservação do meio ambiente. Sob esse aspecto, as políticas públicas voltadas para o meio ambiente devem ser observadas como ferramentas fundamentais para gestão consciente dos recursos naturais, e não como inibidoras de progresso.

\section{REFERÊNCIAS}

ANDRADES, T. O. ; GANAMI, R. N. Revolução Verde e a apropriação capitalista. 2007. Disponível em: <http://intranet.catie.ac.cr/intranet/posgrado/BB507\%20Cambio \%20Global/Documentos/2009/literatura\%20alimentos/En\%20PortugesCapitalismo_Revolucao_verde. pdf>. Acesso em: 10 ago. 2016.

BARBOSA, Hermano Antônio do Cabo. Regulação econômica e tributação: o papel dos incentivos fiscais in Direito Tributário e Políticas Públicas. Coord. José Marcos Domingues. São Paulo: MP Editora, 2008.

BARROS, Pacheco Wellington. O ser e o dever ser do meio ambiente. Jornal Estado de Direito. Porto Alegre, a. IV, n. 27, 2010.

BECK, Ulrich. A sociedade global de risco: uma discussão entre Ulrich Beck e Danilo Zolo. Tradução Andrea Ciacchi, 2000. Disponível em: <http://periodicos. ufpb.br/ojs/index.php/primafacie/article/view/4245/3195>. Acesso em: 10 jul. 2016. 
BERNARDES, Júlia Adão; FERREIRA, Francisco Pontes de Miranda. Sociedade e natureza. In: CUNHA, Sandra Baptista da; GUERRA, Antônio José Teixeira (Orgs.). A questão ambiental: diferentes abordagens. 5. ed. Rio de Janeiro: Bertrand Brasil, 2009.

CAPRA, Fritjof. A teia da vida: uma nova compreensão científica dos sistemas vivos. Tradução de Newton Roberval Eichemberg. São Paulo: Cultrix, 2006.

CORREAA, Darcísio; BACKES, Elton Gilberto. Desenvolvimento sustentável: em busca de novos fundamentos. In: SPAREMBERGER, Raquel Fabiana Lopes; PAVIANI, Jayme (Orgs.). Direito Ambiental: um olhar para a cidadania e sustentabilidade planetária. Caxias do Sul, RS: Educs, 2006.

CORTINA, Adela. Ética Aplicada y democracia radical. 3. ed. Madri: Editorial Tecnos, 2008.

DERANI, Cristiane. Direito ambiental econômico. 3. ed. São Paulo:Saraiva, 2008.

FIGUEIREDO, Guilherme José Purvin de. Curso de Direito Ambiental. 4. ed. São Paulo: Revista dos Tribunais, 2011.

GRAU, Eros Roberto. Elementos de Direito Econômico. São Paulo: RT, 1991.

GRAZIANO DA SILVA, José. A modernização dolorosa: estrutura agrária, fronteira agrícola e trabalhadores rurais no Brasil. Rio de Janeiro: Zahar, 1982.

HAGUENAUER, L. et al. Os complexos industriais na economia brasileira. Texto para Discussão. Rio de Janeiro: IEI / UFRJ. 62:1-72, 1984.

HARVEY, David. Los Límitesdel capitalismo y lateoría marxista. Fondo de Cultura Econônmica, México, 1962.

JONAS, Hans. O princípio responsabilidade: ensaio de uma ética para a civilização tecnológica. Tradução de Marijane Lisboa; Luiz Barros Montez. Rio de Janeiro: Contraponto; PUC-Rio, 2006.

LEITE, José Rubens Morato. Dano Ambiental: do individual ao coletivo extrapatrimonial. São Paulo: Editora Revista dos Tribunais, 2003.

LOCATEL, Celso; AZEVEDO, Francisco Fransualdo de. Desenvolvimento Rural, Política Nacional de Biocombustíveis e o Mito da Inclusão Social no Campo Brasileiro. X Coloquio Internacional de Geocrítica, Barcelona, 2008. Disponível em: <http://www.ub.edu/geocrit/-xcol/313.htm>. Acesso em: 10 jul. 2016.

LUSTOSA, M. C. J., Inovação e tecnologia para uma economia verde: questões fundamentais. Política Ambiental, v. 8, 2011.

MARAFON, Gláucio José. Industrialização da agricultura e formação do Complexo Agroindustrial no Brasil. Disponível em: < http://www.educacaopublica.rj.gov.br/ biblioteca/geografia/0006.html>. Acesso em: 10 jul. 2016.

MARÉS, Carlos Frederico. A função social da terra. Porto Alegre: Sergio Antonio Fabris Editor, 2003.

Introdução ao Direito Socioambiental. In: O direito para o Brasil socioambiental. Org. André Lima. Porto Alegre: Sergio Antonio Fabris Editor, 2002. p.21 a 53. 
MARQUES, José Roberto. O desenvolvimento sustentável e sua interpretação jurídica. São Paulo: Verbatim, 2011.

MEDEIROS, Fernanda Luiza Fontoura de. Meio ambiente: direito e dever fundamental. Porto Alegre: Livraria do Advogado, 2007.

MÜLLER, Geraldo. Complexo Agroindustrial e Modernização Agrária. São Paulo: Ed. Hucitec, 1982.

NUNES, Luís Antônio Rizzato. Manual de Monografia Jurídica. São Paulo: Saraiva, 2002.

NUSDEO, Ana Maria de Oliveira. Defesa da concorrência e globalização econômica. São Paulo: Malheiros, 2002.

NUSDEO, Fabio. Curso de economia: introdução ao direito econômico. 3. ed. São Paulo: RT, 2005.

OST, François. A natureza à margem da lei: a ecologia à prova do Direito. Tradução de Joana Chaves. Lisboa: Instituto Piaget, 1995.

PEREIRA, Juan Pablo Fernández. La seguridad humana. Barcelona: Editorial Ariel, 2006.

SEN, Amartya. Desenvolvimento como liberdade. Tradução de Laura Teixeira Motta. São Paulo: Companhia das Letras, 2010.

SILVA, Maria Beatriz Oliveira da. Desenvolvimento sustentável no Brasil de Lula: uma abordagem jurídico-ambiental. Santa Cruz do Sul: Edunisc; São Paulo: Anita Garibaldi, 2009.

SCHONARDIE, Elenise Felzke. Dano ambiental: a omissão dos agentes públicos. 2. ed. Passo Fundo: UPF, 2005.

VEIGA, José Eli da. Desenvolvimento sustentável: o desafio do século XXI. Rio de Janeiro: Garamond, 2010.

TAVARES, André Ramos. Direito constitucional econômico. São Paulo: Método, 2003.

TRENTINI, Flávia. Teoria Geral do Direito Agrário Contemporâneo. São Paulo: Atlas, 2012.

ZAMBAM, Neuro José. Amartya Sen: liberdade, justiça e desenvolvimento sustentável. Passo Fundo: IMED, 2012.

ZIEGLER, Jean. Os inimigos do direito a alimentação. In: Destruição em massa: Geopolítica da fome. Tradução e prefácio de José Paulo Netto. $1^{\circ}$ ed. São Paulo. Cortez. 2013, p. 151-194. 